\title{
Guidelines versus clinical practice in the treatment of chronic obstructive pulmonary disease
}

\section{To the Editor:}

Chronic obstructive pulmonary disease (COPD) is a very prevalent disease in developed countries. It is estimated that between $7-10 \%$ of the adult population may be affected [1]. In recent years, many scientific societies have published guidelines for the treatment of these patients, one of the most ambitious of which is the Global Initiative for Chronic Obstructive Lung Disease (GOLD) [2]. However, management patterns of the disease in both primary care and specialised settings differ from those proposed by experts. In a recent issue of the European Respiratory Journal, RocHe et al. [3] presented data on the treatment of COPD by respiratory physicians in France. Their results showed that $41.6 \%$ of patients remained untreated. This figure contrasts with the $12 \%$ [4] and 5\% [5] of patients untreated in two different large surveys of primary care in Spain. Similarly, in a populationbased study, only $22 \%$ of patients identified as having COPD in the general population had been diagnosed previously, but among those diagnosed, only $12 \%$ were not receiving any treatment for their respiratory disease [1]. These results highlight important differences in COPD management between the two countries.

Another interesting aspect of their study was the demonstration that treated patients received a mean of 2.6 drugs [3]. In a recent study on moderate-tosevere COPD patients treated by respiratory physicians, we observed that $44 \%$ of patients were receiving at least three different drugs for their respiratory disease [6]. Interestingly, an increased number of drugs prescribed was associated with more severe impairment of health status, as measured by the St George's respiratory questionnaire.

Impairment of the forced expiratory volume in one second $(\mathrm{FEV} 1)$ or baseline dyspnoea was associated with increased prescription of respiratory drugs, with the exception of anticholinergics [3]. In our survey on primary care, impairment in FEV1 was again significantly associated with increased drug prescription, including anticholinergics. However, other factors, such as age, male sex and chronic mucus hypersecretion, explained part of the variability in the prescription of different therapeutic groups [4]. Impairment of FEV1 or baseline dyspnoea was associated with increased prescription of drugs in moderate-to-severe COPD patients managed by respiratory physicians. However, in our study, comorbidity was also significantly associated with increasing treatment in this population [6].

Management of patients with COPD may differ in different countries and over time. A comparison of different studies providing data on COPD management is presented in table 1. It is interesting to observe the large differences in the prescription of different drugs; for example, theophylline use ranges from $10-45 \%$ and inhaled corticosteroids from $26-76 \%$.

Finally, patterns of chronic obstructive pulmonary disease management that adhered more strictly to guidelines were observed in a cross-sectional study. This included performance of lung function tests in the follow-up of patients associated with a lower number of events, such as acute exacerbations or admissions [5], thereby emphasising the importance of implementation of guidelines. New strategies must be designed to diffuse and implement the guidelines among both primary care physicians and respiratory specialists.

\section{Miravitlles}

Servei de Pneumologia, Hospital General Universitari Vall d'Hebron, Barcelona, Spain.

Table 1. - Some studies with data regarding ambulatory treatment of chronic obstructive pulmonary disease (COPD)

\begin{tabular}{|c|c|c|c|c|c|c|c|c|}
\hline First author [ref. no] & Year & Setting & Subjects & FEV1 \% & $\beta_{2}$-agonists & $\mathrm{AC}$ & ICS & Theo. \\
\hline JACKEVICIUS [7] & 1997 & Teaching hospital & 133 & NR & 46 & 25 & 26 & 10 \\
\hline JONES [8] & 1997 & Multicentre hospitals & 283 & 45.1 & NR & NR & 66 & 45 \\
\hline MiraVitLLES [4] & 1999 & Multicentre GPs & 1001 & 47 & 71 & 23 & 50 & 53 \\
\hline VAN ANDEL $^{\#}$ [9] & 1999 & Multicentre hospitals & 676 & 36.4 & 77 & 54 & 41 & 29 \\
\hline MiRAVITLLES [5] & 1999 & Multicentre GPs & 2414 & 56.4 & 56 & 27 & 47 & 43 \\
\hline ROCHE [3] & 2001 & Chest physicians & 631 & 53.6 & 79 & 56 & 76 & 30 \\
\hline MiraVITLLEs [6] & 2002 & Chest physicians & 441 & 36 & 65 & 87 & 69 & 41 \\
\hline
\end{tabular}

FEV1: forced expiratory volume in one second; AC: anticholinergics; ICS: inhaled corticosteroids; Theo.: theophyllines; GPs: general practitioners; NR: not reported. ${ }^{\#}$ : data refers to 1995 . 


\section{References}

1. Sobradillo $\mathrm{V}$, Miravitlles $\mathrm{M}$, Gabriel $\mathrm{R}$, et al. Geographical variations in prevalence and underdiagnosis of COPD. Results of the IBERPOC multicentre epidemiological study. Chest 2000; 118: 981-989.

2. Pauwels RA, Buist AS, Calverley PMA, Jenkins CR, Hurd SS. Global strategy for the diagnosis, management, and prevention of chronic obstructive pulmonary disease. NHLBI/WHO global initiative for chronic obstructive lung disease (GOLD) workshop summary. Am J Respir Crit Care Med 2001; 163: 1256-1276.

3. Roche N, Lepage $\mathrm{T}$, Bourcereau J, Terrioux P. Guidelines versus clinical practice in the treatment of chronic obstructive pulmonary disease. Eur Respir $J$ 2001; 18: 903-908.

4. Miravitlles M, Mayordomo C, Artés M, SánchezAgudo L, Nicolau F, Segú JL on Behalf of the EOLO Group. Treatment of chronic obstructive pulmonary disease and its exacerbations in General Practice. Respir Med 1999; 93: 173-179.

5. Miravitlles M, Murio C, Guerrero T, Segú JL. Tratamiento de la bronquitis crónica y la EPOC en Atención Primaria. Arch Bronconeumol 1999; 35: 173178.

6. Miravitlles M, Alvarez-Sala JL, Lamarca R, et al. Treatment and quality of life in patients with chronic obstructive pulmonary disease. Qual Life Res 2002 (in press).

7. Jackevicius C, Joyce DP, Kesten S, Chapman KR. Prehospitalization inhaled corticosteroid use in patients with COPD and asthma. Chest 1997; 111: 296-302.

8. Jones PW, Bosh TK, in association with an international study group. Quality of life changes in COPD patients treated with salmeterol. Am J Respir Crit Care Med 1997; 155: 1283-1289.

9. Van Andel AE, Reisner C, Menjoge SS, Witek TJ. Analysis of inhaled corticosteroid and oral theophylline use among patients with stable COPD from 1987 to 1995. Chest 1999; 115: 703-707. 